\title{
UM PROJETO INTERDISCIPLINAR: ABORDAGEM TEMÁTICA FREIREANA NO ESTÁGIO DE DOCÊNCIA DO CURSO DE LICENCIATURA INTERCULTURAL INDÍGENA
}

\author{
AN INTERDISCIPLINARY PROJECT: A FREIREAN THEMATIC APPROACH IN \\ TEACHING INTERNSHIP OF INDIGENOUS INTERCULTURAL DEGREE \\ UN PROYECTO INTERDISCIPLINAR: ABORDAJE TEMÁTICA FREIREANA EN LA \\ PRÁCTICA DE DOCENCIA DEL CURSO DE LICENCIATURA INTERCULTURAL \\ INDÍGENA
}

Luci dos Santos Bernardi* lucib@unochapeco.edu.br

\author{
Geovana Mulinari Stuani** \\ geovana.mulinari@gmail.com \\ Nadir Castilho Delizoicov*** \\ ridanc.nadir@gmail.com
}

\begin{abstract}
REVISTA PEDAGÓGICA
Revista do Programa de Pós-graduacão em Educação da Unochapecó | ISSN 1984-1566 Universidade Comunitária da Região de Chapecó | Chapecó-SC, Brasil Como referenciar este artigo: BERNARDI, L. S.; STUANI, G. M.; DELIZOICOV, N. C. Um projeto interdisciplinar: abordagem temática freireana no estágio de docência do curso de licenciatura intercultural indígena. Revista Pedagógica, Chapecó, v. 17, n. 34, p. 192-207, jan/abr. 2015.
\end{abstract}

RESUMO: A Educação Escolar Indígena é uma modalidade da Educação Básica que deve propiciar às populações indígenas, além do acesso a conhecimentos universais, a afirmação das identidades étnicas, a recuperação da memória histórica, a interculturalidade e a valorização da língua materna. O presente trabalho reflete sobre a questão, tomando por base uma experiência desenvolvida no estágio curricular obrigatório nos anos finais do ensino fundamental da educação básica dos universitários do $8^{\circ}$ período do Curso de Licenciatura Intercultural Indígena em Matemática e Ciências da Natureza. O projeto educativo proposto no estágio trabalha a articulação das áreas das Ciências da Natureza e Matemática, com o aporte teórico-metodológico da Abordagem Temática Freireana. Apresentamos uma reflexão acerca da experiência, evidenciando os elementos que constituíram avanços e potencialidades na formação do docente indígena, ancorando as reflexões na concepção freireana de educação, a qual tem sido considerada uma resposta emblemática aos desafios educacionais, percebida como um instrumento para a conquista da autonomia dos povos indígenas.

PALAVRAS-CHAVE: Escola Indígena. Abordagem Temática Freireana. Formação de Professores.

\footnotetext{
ABSTRACT: Indigenous schooling is considered a modality of basic education that should provide indigenous populations, in addition to access to universal knowledge, an affirmation of ethnic identities, a revival of historic memory, interculturality and valorization of the mother language. This study refers to a required curricular internship for university students in the 8th period of the Indigenous Intercultural Teachers College, in mathematics and natural sciences, in which they work in the final years of elementary school. This course initiated in 2009, has been offered at the Xapecó Indigenous Reserve in Ipuaçu, (SC), by the Community
}

University of the Chapecó Region (Unochapecó). The educational project proposed in the internship works with an articulation of the natural sciences and mathematics, with a theoretical-methodological input from the Freirean Thematic Approach. We present a reflection about the experience, revealing elements that constitute advances and potentialities in the education of indigenous teachers.

KEYWORDS: Indigenous School. Freireana Thematic Approach. Teacher Education.

RESUMEN: La educación escolar indígena es una modalidad de Educación Básica que debe propiciar a las poblaciones indígenas, además de acceso a conocimientos universales, a la afirmación de las identidades étnicas, la recuperación de la memoria histórica, la interculturalidad y la valoración de la lengua materna. El presente trabajo refleja sobre la cuestión, basándose en una experiencia desarrollada en la práctica curricular obligatoria en el primer ciclo de la educación secundaria hecha por los universitarios del $8^{\circ}$ periodo lectivo del curso de Licenciatura Intercultural Indígena en Matemática y Ciencia de la naturaleza. El proyecto educativo propuesto en la práctica trabaja la articulación de las áreas de las Ciencias de la naturaleza y matemática, con el aporte teórico metodológico del Abordaje Temática Freireana. Presentamos una reflexión acerca de la experiencia, evidenciando los elementos que constituyeran avanzos y potencialidades en la formación del docente indígena, ancorando las reflexiones en la concepción freireana de la educación, la cual ha sido considerada una respuesta emblemática a los retos educacionales, percibida como un instrumento para la conquista de la autonomía de los pueblos indígenas.

PALABRAS CLAVE: Escuela indígena. Abordaje Temática Freireana. Formación de profesores. 


\begin{abstract}
* Doutora em Educação Científica e Tecnológica pela Universidade Federal de Santa Catarina (UFSC). Professora permanente do Programa de Pós-Graduação stricto sensu em Educação da Universidade Comunitária da Região de Chapecó (Unochapecó).

** Mestre e Doutoranda em Educação Científica e Tecnológica (UFSC). Docente da Área de Ciências Exatas e Ambientais da Universidade Comunitária da Região de Chapecó (Unochapecó).

*** Doutora em Educação pela Universidade Federal de Santa Catarina (UFSC). Professora permanente do Programa de Pós-Graduação stricto sensu em Educação da Universidade Comunitária da Região de Chapecó (Unochapecó). Colaboradora do Programa de Pós-graduação em Educação Científica e Tecnológica da UFSC.
\end{abstract}

\section{INTRODUÇÃO}

A Educação Escolar Indígena, como uma modalidade da Educação Básica, tem como objetivo propiciar às populações indígenas a afirmação das identidades étnicas, a recuperação da memória histórica, a interculturalidade e a valorização da língua materna, além do acesso aos conhecimentos universais. Alcançar esse objetivo não é algo simples. O Referencial Curricular Nacional Indígena - RCNE/ Indígena - aponta que o cotidiano da maior parte dos povos indígenas do Brasil desenrola-se em um contexto de tensão entre conhecimentos indígenas e não indígenas, visto que essas tensões passam pela escola, fazendo-a palco para o diálogo ou o conflito entre forças em interação (BRASIL, 1998).

O presente trabalho aborda a questão a partir do relato de experiências que envolvem o planejamento e a execução do estágio curricular obrigatório efetuado nos anos finais do ensino fundamental da educação básica, dos universitários (cinco) do $8^{\circ}$ período do Curso de Licenciatura Intercultural Indígena em Matemática e Ciências da Natureza. O curso, iniciado em 2009, vem sendo desenvolvido na Terra Indígena Xapecó em Ipuaçu (SC) pela Universidade Comunitária da Região de Chapecó - Unochapecó. Destacamos o processo de planejamento e execução do estágio integrado, desenvolvido pelos acadêmicos estagiários na EEB Cacique Vanckê, que teve como tema gerador (FREIRE, 2008) "o desperdício da água".

\section{CONTEXTUALIZAÇÃO}

O Curso de Licenciatura Intercultural Indígena em Matemática e Ciências da Natureza é oferecido pela Universidade Comunitária da Região de Chapecó (Unochapecó) na Terra Indígena Xapecó, em Ipuaçu/SC, em parceria com a Secretaria Estadual de Educação do Estado de Santa Catarina. As atividades dessa modalidade de licenciatura iniciaram em 2009, atendendo às demandas das comunidades das Terras Indígenas Xapecó, Chimbangue, Pinhal, Palmas e Condá, localizadas nos municípios catarinenses de Ipuaçu, Entre Rios, Abelardo Luz, Chapecó e Seara.

O curso tem por objetivo a formação e a habilitação de professores indígenas para o exercício docente no ensino fundamental em Ciências e Matemática, e no ensino médio em disciplinas específicas de Matemática, Física, Química e Biologia. Está estruturado em uma matriz de formação geral até o quarto período e a partir do quinto período com formação específica nas áreas de Matemática e Ciências da Natureza, perfazendo o total de cinco anos de duração (UNOCHAPECÓ, 2012).

A Etapa de Formação Geral compõe-se de dois núcleos curriculares que se articulam de forma a oportunizar aos estudantes a compreensão dos elementos construtivos 
da educação escolar indígena e os conhecimentos básicos necessários para a prática docente interdisciplinar na educação básica. A Etapa de Formação Específica é desenvolvida nos três últimos anos do curso e terá como enfoque o aprofundamento nos conhecimentos necessários para a prática docente no ensino fundamental e no ensino médio. O Curso de Licenciatura Intercultural Indígena em Matemática e Ciências da Natureza tem como fio condutor um conjunto de temáticas que se desenvolvem a partir dos termos Gênese, Tempo, Espaço, Sociedade, Território e Autonomia, Educação Escolar, Territorialidade e Autonomia dos Povos Indígenas, Práticas Pedagógicas Indígenas e Políticas e Gestão e Financiamento da Educação Escolar Indígena. Esses termos demarcam, de certo modo, a presença de enfoques temáticos articulados, visto que transitam por campos universais. Se, por um lado, há, por exemplo, o estudo e a análise da origem/gênese do homem, da sociedade, das diferentes perspectivas de tempo na história da humanidade, por outro, os conteúdos específicos das temáticas e os problemas elencados para a área específica são mantidos como formação específica.

Assim, as temáticas escolhidas expressam uma compreensão do processo de educação escolar em consonância com uma perspectiva de conhecimentos que se integram, fomentando, desse modo, uma nova prática social e cultural que se constitui tanto pela qualificação teórica universalizante como de endereçamento específico.

O componente curricular Estágio I, ofertado no $8^{\circ}$ período da licenciatura, tem por finalidade proporcionar ao futuro professor a vivência da ação docente nos anos finais do ensino fundamental da educação básica, oportunizando ao universitário uma aproximação com a realidade escolar. Essa aproximação permite o desenvolvimento de atividades teóricas e práticas instrumentalizadoras da práxis docente, refletindo acerca da educação escolar indígena. O estágio tem o desafio de trabalhar os conhecimentos sistematizados das áreas da Matemática e das Ciências da Natureza de forma integrada, a partir da leitura crítica da realidade. Os estudos sobre os saberes da cultura Kaingang são, nesse processo, necessários e fundamentais, assim como o conhecimento institucionalizado nas referidas áreas do conhecimento.

Também foi necessário definir a concepção a ser seguida. Apesar de a concepção educacional de Paulo Freire ser fruto de suas reflexões para a alfabetização de adultos na educação informal, suas ideias tiveram reflexos na educação escolar. Pesquisadores e estudiosos tais como Angotti (1982); Dal Pian et al. (1985); Delizoicov (1982, 1983, 1991); Delizoicov e Castilho (1980); Pernambuco (1983); Pontuschka (1993); Pierson (1997); Torres, O'Cadiz e Wong (2002); Saul e Silva (2009), entre outros, há décadas vêm estudando e propondo a organização curricular a partir das ideias e da concepção freireana de educação. Para tanto, conceitos e demais aspectos dessa concepção passaram por 
um processo de transposição ao serem considerados na educação formal.

Os conceitos de abordagem temática e tema gerador (FREIRE, 2008), entre outros elementos, são fundamentais para práticas educativas na perspectiva freireana de educação. Por meio desses conceitos, balizados pela pesquisa realizada por professores e especialistas, ocorre a identificação de situações significativas para os alunos que as vivem e nelas estão imersos.

Para Delizoicov, Angotti e Pernambuco (2011, p. 273), estudiosos que se dedicam à educação formal, a Abordagem Temática Freireana consiste em uma "[...] perspectiva curricular cuja lógica de organização é estruturada com base em temas, com os quais são selecionados os conteúdos de ensino das disciplinas. Nessa abordagem, a conceituação científica da programação é subordinada ao tema”. Portanto, rompe-se com a abordagem conceitual, segundo a qual a organização curricular e a seleção de conteúdos são estruturadas tendo como base os conceitos científicos. Dessa forma, são os temas que determinarão a organização e a seleção dos conteúdos, como o ponto de partida para se estudar os conceitos que permitirão aos alunos uma compreensão científica do que se está discutindo.

Quanto ao tema gerador - proposto por Freire (2008) em seu clássico livro "Pedagogia do Oprimido" -, na tradução feita para a escola formal, trata-se de

[...] objeto de estudo que compreende o fazer e o pensar, o agir e o refletir, a teoria e a prática, pressupondo um estudo da realidade em que emerge uma rede de relações entre situações significativas individual, social e histórica, assim como uma rede de relações que orienta a discussão, interpretação e representação dessa realidade. (DELIZOICOV; ANGOTTI; PERNAMBUCO, 2011, p. 165).

Trabalhar com o tema gerador significa ter uma visão da realidade com a qual se pretende trabalhar, buscar o rompimento com o senso comum, dar ênfase ao diálogo, incentivar e fornecer condições ao educando para a constante postura crítica problematizadora, fazer a crítica da própria ação, observar a si próprio e discutir no coletivo (DELIZOICOV; ANGOTTI; PERNAMBUCO, 2011, p. 165).

$\mathrm{Na}$ aproximação entre as ideias de Freire e o ensino de Ciências, Delizoicov (2008) apresenta quatro questões que ajudam a pensar uma abordagem temática a partir do tema gerador.

Como se obtém temas geradores para uma determinada escola? 2. Que fatores e variáveis devem ser considerados para estruturar um programa de ensino de ciências que tenha os temas geradores como referência central? 3 . Qual a metodologia de ensino adequada para a sala de aula que contemple as dimensões 
dialógica e problematizadora (FREIRE, 1975, 1977) no processo educativo proposto por Freire? 4. Quais são as mudanças estruturais na prática docente e no cotidiano das escolas que ocorrem pela implementação de uma perspectiva educativa baseada na concepção freireana? (DELIZOICOV, 2008, p. 39).

Podemos observar que, na quarta questão, o autor chama a atenção para uma dimensão da prática docente cuja estrutura é absolutamente distinta da tradicional, a qual Freire denomina de uma relação educando-educador fundamentalmente narrativa ou dissertativa: "Narração de conteúdos que, por isso mesmo, tendem a petrificar-se ou a fazer-se de algo quase morto, sejam valores ou dimensões concretas da realidade. Narração ou dissertação que implica um sujeito - o narrador - e objetos pacientes, ouvintes - os educandos" (FREIRE, 2008, p. 65).

Tema gerador, investigação e abordagem temática constituem elementos fundamentais para uma prática educativa freireana, pois é através deles que se dá a pesquisa de situações significativas para os alunos que as vivem e nelas estão imersos (FREIRE, 2008).

Com essa perspectiva, neste trabalho destacamos o processo de planejamento e de execução do estágio interdisciplinar que teve como tema gerador "o desperdício da água”, desenvolvido pelos acadêmicos estagiários na E. E. B. Cacique Vanckê, na Terra Indígena Xapecó, em Ipuaçu/SC.

\section{AS ATIVIDADES}

As atividades do estágio supervisionado são desenvolvidas no ambiente de trabalho no qual o futuro professor atuará. O objetivo é instrumentalizá-lo para a vida profissional, social, cultural e cidadã. Essa imersão representa, ainda, o desenvolvimento da pesquisa, da investigação, das práticas pedagógicas nas escolas indígenas, constituindo-se como um espaço de articulação da educação indígena e da educação escolar indígena. Esses conceitos dizem respeito, respectivamente, aos conhecimentos tradicionais e próprios da comunidade indígena, e os conhecimentos institucionalizados da educação escolar. Para tanto, são estudados temas e questões emergentes da realidade social e escolar, oportunizando, assim, a apropriação dessa realidade e a sua análise crítica, bem como a proposição de novas formas de fazer educação. Portanto, um dos grandes objetivos do estágio é propiciar o conhecimento da realidade social mediante o desenvolvimento da pesquisa socioantropológica com os estudantes e a comunidade, tomando essa realidade como objeto de reflexão e intervenção, estabelecendo relações dos conhecimentos da área específica com questões de âmbito macrossociais.

O estágio obrigatório da turma em análise teve sua primeira etapa com a "Inserção na Comunidade Escolar 
- Campo de Estágio", no $7^{0}$ período do curso, semestre 2012/2, quando os universitários realizaram observação participante e diagnóstica da realidade escolar.

A observação participante e diagnóstica inseriu os estudantes na vida escolar, pois eles tiveram que observar uma aula de Ciências e uma de Matemática, descrevendo a organização das aulas - o que inclui a interação dos estudantes com os conteúdos trabalhados, a dinâmica de ensino dos docentes e os problemas encontrados, além de entrevistar os docentes das disciplinas. A análise do Projeto Político-Pedagógico da escola de educação básica, descrevendo os seus diferentes componentes, também fez parte desse processo.

A segunda etapa do estágio curricular refere-se à vivência da ação docente nos anos finais do ensino fundamental da educação básica, nas disciplinas de Matemática e de Ciências, com atividades que priorizaram a articulação de saberes historicamente elaborados, o conhecimento da cultura indígena e dos problemas enfrentados pelas comunidades.

Para a discussão sobre o papel do estágio na formação docente, tomamos como base os apontamentos de Pimenta e Lima (2004) sobre "Estágio e Construção da Identidade Profissional Docente”. Com relação ao processo de elaboração do conhecimento, retomaram-se as discussões acerca da interlocução entre os saberes do senso comum e os saberes científicos já realizados em outras disciplinas, como Etnociências, Etnomatemática e Didática das Ciências.

Aprofundou-se, ainda, o estudo sobre a Investigação Temática (FREIRE, 2008) como proposta para elaboração do planejamento de ensino. Freire (2008) salienta que é com a postura ativa da investigação das temáticas que tomamos consciência da realidade e dela nos apropriamos. Nesse sentido, a Investigação Temática ultrapassa a dimensão de uma mera metodologia, envolvendo uma postura pedagógica do docente frente aos homens e suas relações com os outros e com o mundo: "Remete refletir sobre que sociedade está sendo, e que sociedade queremos ajudar a construir, via tomada de consciência de nossa capacidade de intervenção no mundo" (STUANI, 2010, p. 70).

A Investigação Temática, portanto, envolve um processo de investigação e decodificação da realidade, a qual Freire (2008, p. 116-139) organiza em cinco momentos: 1) Levantamento preliminar da área selecionada para trabalho; 2) Análise das situações e escolha das codificações; 3) Diálogos decodificadores; 4) Redução temática; 5) Preparação de atividades para sala de aula.

Em seus estudos, Silva (2004b, 2007) discute e analisa o processo da Investigação Temática e avança na proposição do Contratema (visão de mundo dos professores sobre o Tema Gerador) e das Questões Geradoras (questões que orientam a organização dos conhecimentos que serão trabalhados). Em suas análises, o autor indica, também, um processo para a redução temática, através da 
organização de uma estrutura de sistematização e análise das falas significativas realizadas pelo coletivo de professores, denominado como Rede Temática. Assim, Silva (2004b) organiza a Investigação Temática nos seguintes momentos: a) Levantamento preliminar da realidade local; b) Escolha de situações significativas; c) Caracterização dos temas/contratemas sistematizados na rede temática; d) Elaboração de questões geradoras; e) Construção da programação; f) Preparação das atividades para sala de aula (SILVA, 2004b, p. 7).

A organização metodológica da sala de aula, na atividade analisada neste trabalho, pautou-se nos momentos pedagógicos propostos (DELIZOICOV; ANGOTTI, 2000), sendo eles: Problematização, Organização do Conhecimento e Aplicação do Conhecimento.

No decorrer das atividades, de acordo com essa proposta, o professor compartilha com os estudantes a responsabilidade pela escolha da informação e do uso que se faz dela. Isso proporciona a eles autonomia na construção do seu próprio conhecimento, envolvendo-os com o tema e trabalhando a informação dentro de suas possibilidades. Um dos principais desafios foi o trabalho investigativo proposto, pois essa dimensão educativa não era contemplada: os estudantes, na escola, eram sempre meros espectadores.

\section{O ESTÁGIO}

O Estágio aqui relatado foi desenvolvido em turmas de $6^{\mathrm{a}}$ série da Escola Indígena de Educação Básica Cacique Vanhkrê, na Terra Indígena Xapecó, em Ipuaçu/SC. O planejamento iniciou com a caracterização da escola e da organização didático-metodológica, bem como das turmas. Os estagiários realizaram a pesquisa antropológica com os estudantes das respectivas turmas e com as comunidades desses estudantes objetivando o levantamento das possíveis temáticas a serem trabalhadas.

A pesquisa antropológica organizada pelos estagiários foi aplicada nas turmas onde iriam realizar o estágio. Primeiramente, eles organizaram uma atividade para a coleta de falas contendo situações-problema e questionamentos. Na realização da atividade, eles foram dialogando com os estudantes e anotando depoimentos que consideravam significativos (SILVA, 2004a). Após esse diagnóstico, foram analisados em grupos, segundo um quadro de análise. Esse quadro contém diversos elementos analíticos como: fala significativa, limite explicativo, visão de mundo do professor, problematização, tópicos do conhecimento e áreas. A partir da análise das falas significativas, chegou-se, então, à problemática da falta e do desperdício da água na escola indígena. Em seguida, foram organizadas as programações e, a partir delas, as atividades para a sala de aula.

Os dados da pesquisa foram sistematizados; na sequência, procedeu-se a análise das falas significativas, a escolha dos temas geradores, a elaboração do contratema, a 
problematização e a seleção dos tópicos de conhecimentos necessários para a compreensão das problemáticas referentes ao desperdício de água.

As falas significativas abordaram questões recorrentes da realidade local; porém, com limites explicativos, que geralmente aparecem de forma explícita e pragmática no discurso da comunidade (SILVA, 2004a). Essas falas podem ser definidas como falas coletivas recorrentes da comunidade escolar, suas explicações apresentam limites na forma de entender determinada problemática com um olhar reduzido e imediato para o problema.

Após a análise das falas significativas, definição dos temas geradores e contratema, problematização e seleção dos tópicos do conhecimento, organizaram-se as programações e posteriormente as aulas nos Momentos Pedagógicos (DELIZOICOV; ANGOTTI, 2000), articulando as áreas de Matemática e das Ciências da Natureza. Essa metodologia caracteriza-se como uma proposta para a abordagem de conteúdos, problematizadora e dialógica, organizada em três momentos denominados: Problematização, Organização do Conhecimento e Aplicação do Conhecimento.

O momento inicial, Problematização, tem por finalidade fazer a ligação dos conteúdos a serem estudados com aqueles que o aluno já detém, fruto das interações sociais estabelecidas, ou mesmo com conteúdos já aprendidos na própria escola. Um dos objetivos é propiciar ao professor conhecer as concepções ou conhecimentos prévios dos alunos sobre o que está sendo proposto para discussão. Objetiva-se, também conscientizar o aluno sobre a necessidade de se recorrer ao conhecimento sistematizado na resolução das situações e problemas propostos para estudo. O papel do professor, além de organizar as falas dos alunos, é mais de questionar e lançar dúvidas do que fornecer explicações.

O segundo momento, denominado Organização do Conhecimento, permite ao aluno reconhecer que há outras visões e explicações que melhor elucidam o tema, os problemas e os fenômenos problematizados no momento anterior. O papel do professor, nessa etapa, é organizar estratégias didáticas e materiais que facilitem aos alunos se apropriarem de conceitos e teorias.

A Aplicação do Conhecimento refere-se ao conhecimento sistematizado, do qual o aluno se apropriou, utilizado para analisar e interpretar as situações e os problemas propostos durante a problematização e, também, outras situações que não necessariamente estejam ligadas aos problemas iniciais, mas que podem ser explicadas pelo conhecimento apropriado pelo aluno. O professor precisa organizar estratégias didáticas que proporcionem ao aluno utilizar o conhecimento por ele incorporado para resolver novas questões.

O planejamento feito pelos alunos da experiência aqui em análise foi desenvolvido em 20 aulas, distribuídas entre as disciplinas de Matemática e de Ciências. 
O grande desafio foi articular os diferentes saberes: os institucionalizados em cada área do conhecimento e os tradicionais do povo Kaingang. Trabalhamos na perspectiva de valorização das formas de pensar e de fazer dos indígenas, ancorando nossa proposta nos princípios da Etnociência e da Etnomatemática, com a compreensão de que as práticas e a produção de conhecimentos de Ciências e de Matemática ocorrem em todas as culturas humanas. Para Bernardi (2011), essa articulação é elemento fundamental para a educação escolar indígena, pois um programa educacional que não tenha vínculo com a realidade dos estudantes indígenas pode gerar um enfraquecimento da identidade de todo seu povo, tornando-o mais frágil diante da luta pela sobrevivência. O contrário pode dar mais poder e domínio sobre sua aprendizagem.

Nesse contexto, é necessário pensar a elaboração do conhecimento de forma interdisciplinar, o que exige uma nova postura docente frente ao objeto a ser estudado. Severino (1994) caracteriza a interdisciplinaridade enfocando a dimensão axiológica que envolve questões de natureza política e ética. O autor salienta as relações entre as diferentes dimensões presentes no ato educativo, "[...] o saber não estabelece nexos puramente lógicos entre conceitos e relações formais; ele parece penetrar a dimensão axiológica, envolvendo questões de natureza ética e política. $\mathrm{O}$ saber tem também a ver com o poder e não apenas com o ser e com o fazer" (SEVERINO, 1994, p. 160).

Nesse sentido, Stuani (2010, p. 78) descreve o trabalho interdisciplinar como uma mudança de postura:

[...] trabalhar interdisciplinarmente, requer uma mudança de postura frente ao conhecimento e ao ato educativo; exige busca constante por novos conhecimentos e um maior diálogo entre as áreas do conhecimento. Portanto, pensar o conhecimento em sua totalidade envolve romper com as barreiras que individualizam as disciplinas, buscando perceber as interfaces que ligam os diferentes saberes na compreensão dos fenômenos estudados. Diria que o sentido do interdisciplinar está na contribuição das áreas do conhecimento, no entendimento de um objeto de estudo comum, desvelando as várias dimensões que o envolvem, dando um sentido de totalidade.

O diálogo entre os diferentes saberes em torno de um problema comum é um dos pressupostos da pedagogia freireana. Freire (2008, p. 114-115), no seguinte trecho, analisa a importância da interdisciplinaridade:

Estes temas devem ser classificados num quadro geral de ciências, sem que com isto signifique, contudo, que sejam vistos, na futura elaboração do programa, como fazendo parte de departamentos estanques. Significa 
${ }^{1}$ Foram entrevistados dois acadêmicos formandos, que já haviam finalizado o estágio. A fim de preservar a identidade deles, serão denominados como Acadêmico 1 e Acadêmico 2. apenas, que há uma visão mais específica, central de um tema, conforme a sua situação num domínio qualquer das especializações.

Salientamos que, na análise das falas significativas coletadas pelos estudantes-estagiários, outras áreas, além de Ciências da natureza e Matemática, foram elencadas para a compreensão do problema. Contudo, ressaltamos neste relato somente as duas citadas anteriormente, tendo em vista a dinâmica de organização do estágio com a articulação entre elas.

Portanto, pensar o conhecimento escolar de forma interdisciplinar, na educação escolar indígena, a partir dos problemas da comunidade, pode constituir-se como um instrumento de garantia de acesso ao saber elaborado de forma mais ampla, permitindo o empoderamento das comunidades indígenas na luta pelos seus direitos.

\section{ANÁLISE E DISCUSSÃO}

O trabalho na Abordagem Temática Freireana tem sido considerado uma possibilidade real e efetiva para o enfrentamento dos desafios educacionais, sendo percebido como um instrumento para o desenvolvimento da autonomia dos povos indígenas. No decorrer das atividades, o docente assume uma nova postura diante da seleção dos conhecimentos a serem trabalhados, uma vez que considera o diálogo com os educandos como parte inerente do processo de seleção e elaboração de novos conhecimentos. Essa atitude epistemológica diante do saber, estabelecendo relações entre o senso comum e o conhecimento científico, traduz-se em um maior envolvimento dos educandos com o tema, tornando o ato de aprender uma busca coletiva por respostas a problemas reais e cotidianos. Esse foi também o principal desafio ao propormos as atividades no estágio: a busca de um trabalho com caráter investigativo. A expectativa surge porque as aulas até então por eles desenvolvidas não propunham atividades nas quais os educandos exerciam uma ação investigativa; eles eram sempre meros espectadores. As observações demonstraram que a lógica centrava-se no uso do livro didático de forma linear, sem relacionar com o cotidiano.

A elaboração do conhecimento a partir da realidade e dos conhecimentos prévios dos estudantes possibilitou desencadear um novo processo educativo na educação escolar indígena. Conforme se percebe nas falas dos acadêmicos": "As aulas foram tão prazerosas para os alunos que os mesmos não queriam que eu parasse de trabalhar com eles" (ACADÊMI$\mathrm{CO}$ 2); "A turma apresentava interesse nas ações educativas realizadas. [...] Foram bastante participativos e os alunos colaboravam uns com os outros" (ACADÊMICO 1).

Outro ponto importante a destacar no trabalho interdisciplinar, a partir dos problemas da comunidade, encontra-se na forma de conceber o conhecimento. Essa 
nova compreensão concebe que os processos de ensino e de aprendizagem de Ciências e de Matemática podem ser desenvolvidos em uma perspectiva social e política, e a educação desenvolvida nessa perspectiva pode trazer contribuições para proporcionar melhorias à vida da comunidade.

Nesse sentido, Freire (1999) explicita que ensinar exige a apreensão da realidade, além da capacidade de aprender, não de simplesmente se adaptar, mas de perceber a possibilidade de mudança, contribuição esta presente na fala de um dos acadêmicos: "Através disso, podemos perceber a importância de trazer para a sala de aula as causas e os problemas locais que afetam todos" (ACADÊMICO 1).

A dimensão da interdisciplinaridade também é reconhecida no fazer dos acadêmicos durante o estágio como relevante no processo de ensino aprendizagem, conforme se percebe nas falas a seguir:

Ainda é importante ressaltar que, por se trabalhar interdisciplinarmente, os estudantes demoraram um pouco a se adaptar. Mas depois correu tudo bem: conseguiram apreender algumas coisas, conceitos. Enfim, estou satisfeita, pois consegui repassar algo de bom e de importante para eles. (ACADÊMICO 2).

Trata-se de tomar a unidade e compreendê-la na totalidade. (ACADÊMICO 1).

Na busca por compreender os problemas locais que afetam a comunidade indígena, os educadores perceberam a necessidade da pesquisa, bem como a importância da sua ação no desenvolvimento dos sujeitos. Nesse processo de ação-reflexão-ação sobre o seu fazer pedagógico, os sujeitos vão constituindo sua identidade docente. Pimenta e Lima (2004) salientam que a identidade do professor é construída ao longo de sua trajetória profissional; porém, é no processo de formação que suas opções e intenções são consolidadas.

Outra questão importante a destacar é a compreensão de que os processos de ensino e de aprendizagem de Matemática e de Ciências podem ser desenvolvidos em uma perspectiva social e política. Uma educação desenvolvida nessa perspectiva pode trazer contribuições para pensar uma transformação da realidade.

Para Freire (2002), a educação tem papel fundamental para elevar o nível de consciência dos alunos sobre as suas condições de vida e fornecer-lhes instrumentos para que possam atuar visando à transformação da sua realidade. Nesse sentido, esse autor considera que ensinar exige a apreensão da realidade, percebendo a possibilidade de mudança.

Nesse sentido, cabe destacar as seguintes falas dos acadêmicos:

Esta experiência de exercitar a docência nas escolas, durante a vida acadêmica, nos 
proporcionou grande realização pessoal e profissional, pois é diante destes desafios que conseguimos construir conhecimentos para realizar futuramente uma prática educativa coerente, capaz de fazer com que atuemos de maneira mais eficiente e qualificada. (ACADÊMICO 1).

[...] através disso, podemos perceber a importância de trazer para a sala de aula as causas e os problemas locais que afetam todos. (ACADÊMICO 2).

O inacabamento e a busca do ser mais são uma constante na pedagogia progressista, refletindo na postura pedagógica dos educadores quando esses, em contato com ela, compreendem a profundeza de seus pressupostos (FREIRE, 2008). Percebemos isso nos seguintes relatos acerca das mudanças percebidas nos envolvidos neste processo:

Olha professora, eu seguia mais o livro. Bem... Só o livro praticamente. Agora, penso numa aula mais prática. Não vejo professores trabalhando na escola assim. Nunca vi. Acho que as crianças vão gostar. (ACADÊMICO 2).

Eu também acho que as crianças vão gostar. Eu nunca dei aula. Mas acompanho minhas filhas, e é sempre a mesma coisa: a aula se resume ao livro. (ACADÊMICO 1).

O livro didático representa uma das condições tradicionais da prática de sala de aula, da cultura do "homem branco", sendo os problemas formulados por uma autoridade externa à sala de aula, à comunidade. Em relação aos conteúdos, os exercícios e os problemas com os quais os alunos trabalham são compostos por uma ciência e uma Matemática prontas e acabadas.

A mudança nesse processo não é uma tarefa fácil, exige do educador romper com a transmissão e perceber que ensinar não é transferir conhecimentos, mas criar as possibilidades de sua criação e recriação. Exige, portanto, uma postura dialógica do educador com o educando (FREIRE, 2002). Esse novo paradigma se dá através da busca, seleção, organização e manipulação de informações, e exige pesquisa e rigorosidade metódica. É um processo que envolve, acima de tudo, uma pedagogia da pergunta.

Indagar, problematizar e investigar são processos também considerados por Bachelard (1977, p. 48) para o qual se "[...] não tiver questão, não pode haver conhecimento científico". Para o autor, a formulação de um problema, de um questionamento é fundamental, tanto para a produção do conhecimento científico quanto para o processo de ensino aprendizagem. É o que também reforçam Freire e Faundez (1985, p. 46): 
O que o professor deveria ensinar - porque ele próprio deveria sabê-lo - seria, antes de tudo, ensinar a perguntar. Porque o início do conhecimento, repito, é perguntar. E somente a partir de perguntar é que se deve sair em busca de respostas e não o contrário: estabelecer as respostas, com o que todo o saber fica justamente nisso, já está dado, é um absoluto, não cede lugar à curiosidade nem a elementos para o descobrir. O saber já está feito, este é o ensino.

Indagar e investigar são processos inseparáveis que requerem dos estudantes uma participação ativa e cabe ao professor a responsabilidade de integrá-los de forma que se sintam convidados a participarem da atividade.

Sendo assim, essa perspectiva requer um processo de formação permanente com vistas a superar diferentes dificuldades que emergem no decorrer do processo. Dentre as dificuldades apontadas pelos estagiários, salientamos:

Na verdade, no início a gente estava bastante nervoso e preocupado., não sabia o que nos esperava, [...] a dúvida de saber se sabia fazer uma proposta tão diferente. Tinha medo do que nos esperava. Hoje, podemos ver que não foi tão difícil. Mas falta ainda detalhar os conteúdos. (ACADÊMICO 1).

Nós não vamos ter que estar preparados só para dar isso (o planejado). Temos que estudar um bom tanto a mais e, ainda, corremos o risco de levar uma surpresa dos alunos e de não saber responder algo. (ACADÊMICO 2).

Tenho muita dificuldade para pensar a Matemática junto. Quando a professora fala, parece simples; mas, na hora que vou escrever... Se fosse só revisar os conteúdos, [...] Mas chegar aos conceitos é difícil. (ACADÊMICO 1).

Se me sinto seguro em relação aos conceitos? Mais ou menos, professora. Antes eu achava que sabia bem, agora nem tanto. (ACADÊMI$\mathrm{CO} 2)$.

A partir desses relatos, salientamos dois aspectos importantes: a fragilidade conceitual referente à área de conhecimento - nesse caso de Matemática, e a consequente dificuldade de trabalhar com os conteúdos para a compreensão da problemática, para elaboração de possíveis intervenções e para a formalização de conceitos.

\section{CONSIDERAÇÕES FINAIS}

A proposta do curso nas áreas de Matemática e Ciências da Natureza para professores indígenas teve como eixo principal a história da construção dos diferentes 
conhecimentos, dentre eles o científico, como fruto das inter-relações entre sociedade-natureza-ciência-tecnologia. Sob tais paradigmas, buscamos estabelecer complementaridade entre os diferentes saberes, tendo como ponto de partida e como objeto de estudo os conhecimentos próprios da comunidade educativa que participa do curso.

A formação proposta para os professores indígenas kaingang que ensinam Ciências e Matemática evidenciou possibilidades na medida em que os educadores participantes conseguem atentar para a construção, em suas escolas, de um cenário que possibilite a investigação, abrindo espaços para ação e para reflexão - características da educação libertadora.

A proposta de estágio indica caminhos de reflexão acerca da aproximação e do entrelaçamento entre teoria e prática, do respeito aos saberes dos estudantes, da valorização da cultura. Um exercício do "fazer" docente que oportuniza uma educação na qual os professores e os estudantes indígenas possam, de fato, serem sujeitos dialógicos no ato de aprender, com seu contexto, seus saberes e sua história e, assim, mobilizarem-se para ter uma posição crítica no mundo, a partir dos diferentes conhecimentos da ciência e da Matemática.

\section{REFERÊNCIAS}

ACADÊMICO 1. Entrevista. [20 jun. 2014]. Entrevistador: Geovana Mulinari Stuani e Luci dos Santos Bernardi. TI Xapecó, Ipuaçu, 2014. 1 arquivo.mp3 (115 min).

ACADÊMICO 2. Entrevista. [[20 jun. 2014]. Entrevistador: Geovana Mulinari Stuani e Luci dos Santos Bernardi. TI Xapecó, Ipuaçu,2014. 1 arquivo.mp3 (108 min).

ANGOTTI, J. A. P. Solução alternativa para a formação de professores de ciências. 1982. 143 f. Dissertação (Mestrado em Educação) - Programa de Pós-Graduação em Educação, Universidade de São Paulo, São Paulo, 1982.

BACHELARD, G. O materialismo aplicado. Rio de Janeiro: Zahar, 1977.

BERNARDI, L. T. M. dos S. Formação continuada em matemática do professor indígena kaingang: enfrentamentos na busca de um projeto educativo. 2011. 267 f. Tese (Doutorado em Educação Científica e Tecnológica) - Programa de Pós-Graduação em Educação, Universidade Federal de Santa Catarina, Florianópolis, 2011.

BRASIL. Ministério da Educação e do Desporto. Secretaria de Educação Fundamental. Referencial curricular nacional para as escolas indígenas. Brasília: MEC/ SEF, 1998. 
DAL PIAN et al. Seca e água - material de apoio. Natal: Editora Universitária UFRN, 1985.

DELIZOICOV, D. Concepção problematizadora do ensino de ciências na educação formal. 1982. $133 \mathrm{f}$. Disssertação (Mestrado em Ensino de Ciências) - Programa de Pós-Graduação em Educação, Universidade de São Paulo, São Paulo, 1982.

. Conhecimento, tensões e transições. 1991. ooo f. Tese (Doutorado em...) - Programa de Pós-Graduação em Educação, Universidade... FEUSP?, São Paulo, 1991.

. O ensino de física e a concepção freireana da educação. Revista de Ensino de Física, v. 5, n. 2, p. 85-98, dez. 1983.

DELIZOICOV, D. La educación en ciencias y la perspectiva de Paulo Freire. In:

Alexandria: Revista de Educação em Ciência e Tecnologia, v. 1, n. 2, p. 37-62, jul. 2008.

DELIZOICOV, D; ANGOTTI, J. A. Metodologia do Ensino de Ciências. São Paulo: Cortez, 2000.

.; ANGOTTI, J. A.; PERNAMBUCO, M. M. Ensino de Ciências: fundamentos e métodos. São Paulo: Cortez Editora, 2011.

.; CASTILHO, N. Ciências Naturais - Livro do Aluno $-5^{\text {a }}$ Classe. Bissau: Imprensa Nacional da Guiné Bissau, 1980a.

FREIRE, $P$. Pedagogia da autonomia. Rio de Janeiro: Paz e Terra, 2002.

Pedagogia do oprimido. Rio de Janeiro: Paz e Terra, 2008.

.; FAUNDEZ, A. Por uma pedagogia da pergunta. Rio de Janeiro: Paz e Terra, 1985.

PERnAMbUCO, M. M. C. Projeto ensino de ciências a partir de problemas da comunidade: uma experiência no Rio Grande do Norte. Natal: UFRN; Brasília: CAPES/MEC/SPEC, 1983.

PIMENTA, S. G.; LIMA, M. S. L. Estágio e docência. São Paulo: Cortez, 2004.

PIERSON, A. H. C. O cotidiano e a busca de sentido para o ensino de Física. 1997. $241 \mathrm{f}$. Tese (Doutorado em Educação) - Programa de Pós-Graduação em Educação, Universidade de São Paulo - USP, São Paulo, 1997. 
PONTUSCHKA, N. (Org.). Ousadia no diálogo - Interdisciplinaridade na escola pública. São Paulo: Edições Loyola, 1993.

SAUL, A. M.; SILVA, A. F. G. O legado de Paulo Freire para as políticas de currículo e para a formação de educadores no Brasil. Revista Brasileira de Estudos Pedagógicos, Brasília, v. 90, n. 224, p. 223-244, jan./abr. 2009.

SEVERINO, A. J. Filosofia. São Paulo: Cortez, 1994.

SILVA, A. F. G. da. A construção do currículo na perspectiva popular crítica: das falas significativas às práticas contextualizadas. 2004. 405 f. Tese (Doutorado em Educação) - Programa de Pós-Graduação em Educação, Universidade Católica de São Paulo - PUC, São Paulo, 2004a.

. O currículo na práxis da Educação Popular: projeto pedagógico interdisciplinar, tema gerador via rede temática. In: PREFEITURA MUNICIPAL DE CHAPECÓ. Secretaria Municipal de Educação. Caderno de Visão de Área: Ciências. 2004b. p. 07.

.; SOUZA, A. I. (Org.). A busca do tema gerador na práxis da educação popular. Curitiba: Editora Gráfica Popular, 2007.

STUANI, G. M. A construção curricular popular crítica no ensino de ciências naturais e suas implicações na prática docente. 2010. 194 f. Dissertação (Mestrado em Educação) - Programa de Pós-Graduação em Educação, Universidade Federal de Santa Catarina, Florianópolis, 2010.

TORRES, C. A.; O'CADIZ, M. P.; WONG, P. L. Educação e democracia - a práxis de Paulo Freire em São Paulo. São Paulo: Cortez; Instituto Paulo Freire, 2002.

UNOCHAPECÓ. Projeto pedagógico do curso de licenciatura intercultural indígena em matemática e ciências da natureza. Chapecó: UNOCHAPECÓ, 2012. 